\title{
A comparison of the Rescorla-Wagner and Pearce models in a negative patterning and a summation problem
}

\author{
KARYN M. MYERS, EDGAR H. VOGEL, JENNIFER SHIN, and ALLAN R. WAGNER \\ Yale University, New Haven, Connecticut
}

\begin{abstract}
In two experiments, we examined two related conditioning problems previously investigated by Redhead and Pearce (1995a) and Pearce, Aydin, and Redhead (1997). Experiment 1 involved an A+, B+, C+, $\mathrm{AB}+, \mathrm{AC}+, \mathrm{BC}+, \mathrm{ABC}-$ discrimination. The Rescorla-Wagner model predicts that response to $\mathrm{AB}, \mathrm{AC}$, and $\mathrm{BC}$ will be greater than that to $\mathrm{A}, \mathrm{B}$, and $\mathrm{C}$ at asymptote, whereas the Pearce model makes the opposite prediction. In Experiment 2, we investigated the responding to a novel $\mathrm{ABC}$ compound in groups trained with either $\mathrm{A}+, \mathrm{B}+, \mathrm{C}+$ or $\mathrm{AB}+, \mathrm{AC}+, \mathrm{BC}+$. The Rescorla-Wagner model predicts greater response to $\mathrm{ABC}$ in the group trained with $\mathrm{A}+, \mathrm{B}+, \mathrm{C}+$ than in the group trained with $\mathrm{AB}+, \mathrm{AC}+, \mathrm{BC}+$, whereas the Pearce model makes the opposite prediction. In contrast to the findings of Redhead and Pearce (1995a) and Pearce et al. (1997) in pigeon autoshaping, our findings in rabbit eyelid conditioning support the Rescorla-Wagner model.
\end{abstract}

Considerable recent evidence (e.g., Pearce \& Wilson, 1990a, 1991a, 1991b; Wilson \& Pearce, 1989, 1992; Young \& Pearce, 1984) points to a more significant role of configural cues in Pavlovian conditioning than might have been anticipated from prevailing elementistic accounts (e.g., Rescorla \& Wagner, 1972). Indeed, the weight of the evidence has been interpreted by Pearce $(1987,1994)$ as indicating that CS representation is basically configural, rather than elementistic.

The majority of the available data can be handled by either an elementistic theory that includes added configural elements (e.g., Spence, 1952; Wagner \& Rescorla, 1972) or Pearce's configural theory (see Wagner \& Brandon, 2001). But, a series of studies from Pearce's laboratory, done with pigeon autoshaping and combinations of visual stimuli (Aydin \& Pearce, 1994; Pearce, Aydin, \& Redhead, 1997; Pearce \& Redhead, 1993; Pearce \& Wilson, 1990b; Redhead \& Pearce, 1995a, 1998), appear more congruent with a configural account.

Because of the theoretical importance of these studies, we have sought to evaluate the generality of these findings by repeating the formal comparisons involved, but using eyelid conditioning in the rabbit and compounds of stimuli drawn from different sensory modalities. In a dissertation conducted in our laboratory, Bahçekapılı (1997) repeated the design of Pearce and Redhead (1993), and obtained a quite different pattern of results than did the original investigators. We will describe these studies in a later section. The two experiments that we now report were

Jennifer Shin is now at New York University. This research was supported in part by National Science Foundation Grant IBN-9728896 to A.R.W. Correspondence concerning this article should be addressed to A. R. Wagner, Department of Psychology, Yale University, P. O. Box 208205, New Haven, CT 06520-8205 (allan.wagner@yale.edu). similarly aimed at evaluating the generality of the observations of Redhead and Pearce (1995a, Experiments 2, 3 , and 4) and Pearce et al. (1997, Experiment 1). The comparisons made in the two experiments lead to clear differential predictions from the Rescorla-Wagner (1972; Wagner \& Rescorla, 1972) and the Pearce $(1987,1994)$ models, due to their differing conceptions of the effective stimulus.

According to the Rescorla-Wagner conception, any compound stimulus comprises multiple elements, each of which forms a separate association with the unconditioned stimulus (US). In this vein, Wagner and Rescorla (1972; see also Wagner, 1971) supposed that a compound stimulus, $\mathrm{AB}$, could be considered to comprise the elements $\mathrm{A}$ and $\mathrm{B}$, as well as a "configural" element, $A B$, representing those stimulus attributes unique to the joint presentation of $\mathrm{A}$ and $\mathrm{B}$. The associative strength of the compound is said to be equal to the sum of the separate associative strengths, $\mathrm{V}_{\mathrm{A}}+\mathrm{V}_{\mathrm{B}}+\mathrm{V}_{A B}$, whether these strengths are acquired by direct training of $\mathrm{AB}$ or through the training of other stimuli in which the components also occur and are similarly expressed - that is, by generalization.

According to the Pearce conception, each compound is a unique configuration that has a unitary direct association with the US. However, in addition to the associative strength that is directly conditioned to a configuration, $\mathrm{E}_{i}$, there is also that strength, $\mathrm{e}_{i}$, which generalizes from other configurations that contain any of the same components. Thus, a compound stimulus, $\mathrm{AB}$, is said to have a total associative strength equal to the sum of $\mathrm{E}_{\mathrm{AB}}+{ }_{j} \mathrm{e}_{\mathrm{AB}}$ $+\ldots+{ }_{n} \mathrm{e}_{\mathrm{AB}}$, where the latter terms represent the generalization to $\mathrm{AB}$ from configurations $j, \ldots, n$ that include components $\mathrm{A}$ or $\mathrm{B}$. The proportion of the associative strength of configuration $j, \mathrm{E}_{j}$ that generalizes to configuration $i$ as ${ }_{j} \mathrm{e}_{i}$ is given by ${ }_{j} \mathrm{~S}_{i}$, the proportion of the ele- 
ments in configuration $j$ that are common to the two configurations times the proportion of elements in $i$ that are common to the two configurations.

Beyond these major differences, the two models compute similarly. Rescorla and Wagner suppose that the change in the associative strength of each of the components, $\Delta \mathrm{V}_{i}$, on an AB trial is equal to $\alpha \beta\left[\lambda-\left(\mathrm{V}_{\mathrm{A}}+\mathrm{V}_{\mathrm{B}}\right.\right.$ $\left.\left.+\mathrm{V}_{A B}\right)\right]$, where $\lambda$ is the asymptotic associative strength supported by the US on that trial and $\alpha$ and $\beta$ are learning rate parameters. Pearce supposes, analogously, that the change in the directly conditioned associative strength of the configuration, $\Delta \mathrm{E}_{\mathrm{AB}}$, on an $\mathrm{AB}$ trial is equal to $\beta$ $\left[\lambda-\left(\mathrm{E}_{\mathrm{AB}}+{ }_{j} \mathrm{e}_{\mathrm{AB}}+\ldots+{ }_{n} \mathrm{e}_{\mathrm{AB}}\right)\right]$, where $\beta$ and $\lambda$ are identified as in the Rescorla-Wagner equation.

The two studies of Pearce and his colleagues that we attempted to replicate each involved the same set of nominal stimuli, including three one-term cues (A, B, and $\mathrm{C})$, three two-term cues ( $\mathrm{AB}, \mathrm{AC}$, and $\mathrm{BC})$, and a threeterm compound ( $\mathrm{ABC}$ ). In Experiment 1, we examined the learning of a "negative patterning" discrimination in which each of the one- and two-term cues was reinforced but the three-term compound was nonreinforced. In this case the concern was with the magnitude of response to $\mathrm{A}, \mathrm{B}$, and $\mathrm{C}$ versus that to $\mathrm{AB}, \mathrm{AC}$, and $\mathrm{BC}$, at asymptote. In Experiment 2, separate groups of animals were given reinforced training with either the three one-term cues or the three two-term cues before being identically tested for their response to the novel $\mathrm{ABC}$ cue.

\section{EXPERIMENT 1}

A negative-patterning problem is one in which several different stimuli are separately reinforced but an aggregation of the same stimuli is nonreinforced. That animals can solve such a discrimination has been known since the work of Woodbury (1943), and, more recently in eyeblink conditioning, by the study of Whitlow and Wagner (1972), both using the simple case of $\mathrm{A}+, \mathrm{B}+, \mathrm{AB}-$. Both the Rescorla-Wagner model (Wagner \& Rescorla, 1972) and the Pearce model (1987) can account for the essential fact of less responding to the nonreinforced compound as compared with the reinforced components, but they make different predictions in some instances about the degree of responding to the various component stimuli. Redhead and Pearce (1995a, Experiments 2, 3, and 4) set up a relatively complex negative-patterning discrimination involving $\mathrm{A}+, \mathrm{B}+, \mathrm{C}+, \mathrm{AB}+, \mathrm{AC}+, \mathrm{BC}+, \mathrm{ABC}-$, in which clear differences are predicted.

Figure 1 depicts the associative strengths that are predicted to accrue over trials to the classes of training stimuli in an $\mathrm{A}+, \mathrm{B}+, \mathrm{C}+, \mathrm{AB}+, \mathrm{AC}+, \mathrm{BC}+, \mathrm{ABC}-$ discrimination according to the Pearce model (left panel) and the Rescorla-Wagner model (right panel). ${ }^{1}$ Each of the models predicts that as a result of training there will eventually be greater associative strength exhibited to each of the reinforced stimuli, including the three single-term stimuli, A, B, and C, and the three double-term stimuli, $\mathrm{AB}, \mathrm{AC}$, and $\mathrm{BC}$, than to the nonreinforced triple-term compound, $\mathrm{ABC}$. The differential prediction of the two models is in the relative associative strengths that should be exhibited by the single-term stimuli versus the doubleterm stimuli, at this point in training. As is shown in the left panel of Figure 1, the Pearce model anticipates that greater associative strength will be exhibited to $\mathrm{A}, \mathrm{B}$, and $\mathrm{C}$ than to $\mathrm{AB}, \mathrm{AC}$, and $\mathrm{BC}$. In contrast, as is shown in the right panel of Figure 1, the Rescorla-Wagner model anticipates that greater associative strength will be exhibited to $\mathrm{AB}, \mathrm{AC}$, and $\mathrm{BC}$ than to $\mathrm{A}, \mathrm{B}$, and $\mathrm{C}$. The Pearce model gives computational emphasis to the reasoning that the two-term stimuli are more similar to the nonrein-

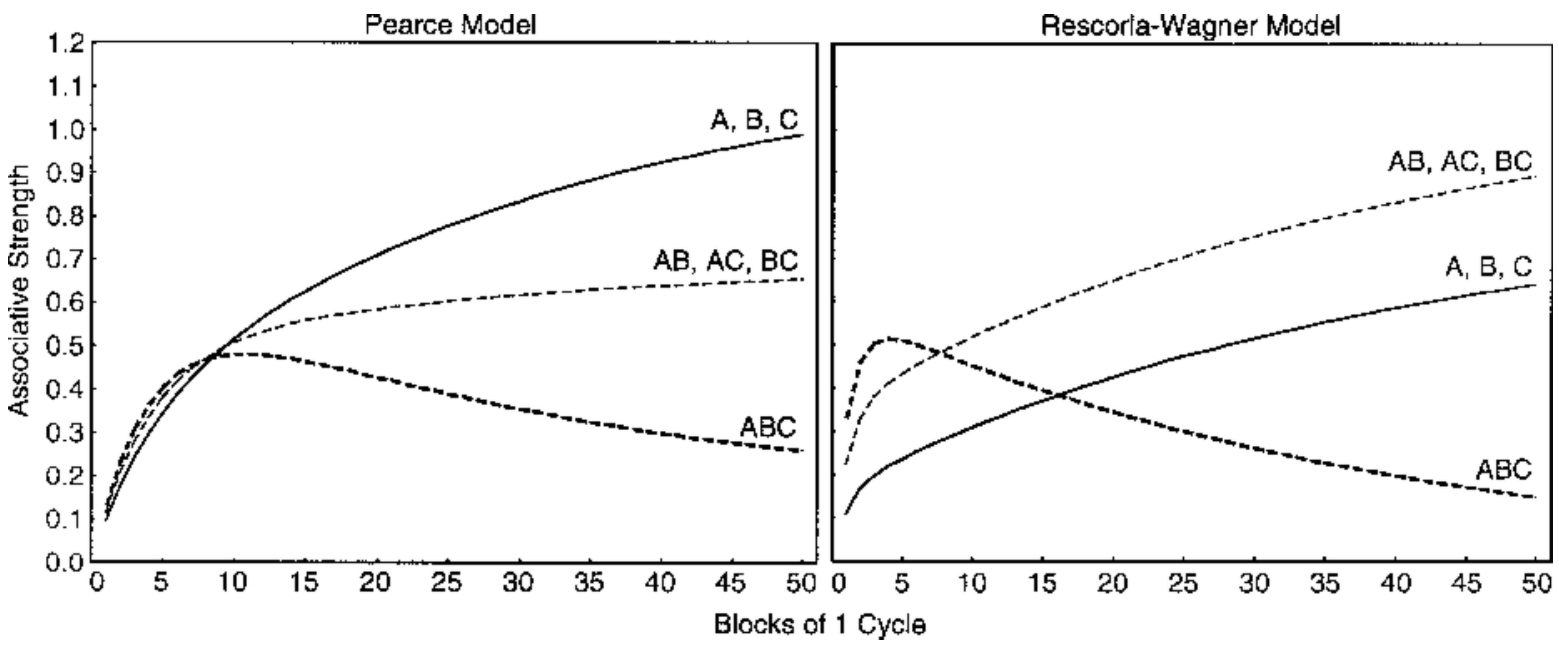

Figure 1. Changes in associative strength predicted for the learning of an $\mathrm{A}+, \mathrm{B}+, \mathrm{C}+, \mathrm{AB}+, \mathrm{AC}+, \mathrm{BC}+, \mathrm{ABC}-\mathrm{negative}$ patterning problem by a computer simulation of the Pearce model (left graph) and by a computer simulation of the Rescorla-Wagner model (right graph). The Pearce model predicts that the aggregate associative strength of the one-component CSs (A, B, and C) will be greater than that of the two-component CSs (AB, AC, and BC), whereas the Rescorla-Wagner model predicts the opposite. 
forced $\mathrm{ABC}$ than are the single-term stimuli, whereas the Rescorla and Wagner model gives computational emphasis to the reasoning that the two-term stimuli profit from the summation of the associative strengths exhibited by the one-term stimuli that they include.

Redhead and Pearce (1995a, Experiments 2, 3, and 4) investigated the acquisition of the $\mathrm{A}+, \mathrm{B}+, \mathrm{C}+, \mathrm{AB}+, \mathrm{AC}+$, $\mathrm{BC}+, \mathrm{ABC}-$ problem in a visual discrimination task with pigeons. In these experiments, the $\mathrm{A}, \mathrm{B}$, and $\mathrm{C}$ cues were, respectively, represented by a number of small $(0.13 \times$ $0.14 \mathrm{~cm}$ ) red, green, and yellow rectangles that were displayed in random arrangements on a $5.5 \times 4.4 \mathrm{~cm}$ television screen, located behind a Perspex "key" on which the pigeons pecked. In Experiment 2, the A, B, and C cues were each represented by 100 rectangles when presented in isolation; by 50 rectangles when presented in compound as $\mathrm{AB}, \mathrm{AC}$, or $\mathrm{BC}$; and by 33 rectangles when presented in compound as $\mathrm{ABC}$. In Experiments 3 and 4, the number of rectangles representing each of the three cues in the different compounds was varied in other ways. In support of the Pearce prediction and contrary to the RescorlaWagner prediction, the overall level of response to A, B, and $\mathrm{C}$ was found to be higher than that to $\mathrm{AB}, \mathrm{AC}$, and $\mathrm{BC}$ in each of the three experiments.

Experiment 1 was an attempt to evaluate the same formal negative patterning discrimination studied by Redhead and Pearce (1995a). It differed from the studies by Redhead and Pearce in that we employed rabbit eyelid conditioning and used cues drawn from different-visual, auditory, and vibrotactual - modalities as A, B, and C.

\section{Method}

Animals. The animals were 8 experimentally naive male New Zealand white rabbits (Oryctolagus cuniculus) weighing between 2 and $3 \mathrm{~kg}$ at the start of training. Each was individually housed and maintained with ad libitum food and water, except during experimental sessions.

Apparatus. Training was conducted in eight identical $66 \times$ $48 \times 48 \mathrm{~cm}$ isolation chambers, allowing all rabbits to be run concurrently. Each chamber was completely lined with aluminum foil to provide a homogeneous visual surround and illuminated by a 1 -W neon bulb. Ventilation fans provided a constant background masking noise that raised the ambient sound pressure level to approximately $70 \mathrm{~dB}$ (re $20 \mu \mathrm{N} / \mathrm{m}^{2}$ ) in each chamber. During experimental sessions the rabbit was loosely restrained within a chamber by a $51 \times 18 \times 14 \mathrm{~cm}$ Plexiglas box, from which its head protruded.

Three conditioned stimuli (CSs) were employed. The first was a $3000-\mathrm{Hz}$ tone, presented through a loudspeaker located behind the subject on the rear wall of the chamber. It raised the ambient sound pressure by $20 \mathrm{~dB}$, measured at the locus of the rabbit's head. The second was a $12 / \mathrm{sec}$ flashing light generated by a strobe lamp located behind the subject so as to reflect diffusely from the walls of the chamber. The third was a $30-\mathrm{Hz}$ oscillation provided by a hand massager mounted on the floor of the restraining box so as to maintain firm contact with the animal's chest. All subjects received all three of these cues, with the tone designated as A, the light as B, and the vibrator as $\mathrm{C}$. Each $\mathrm{CS}$ was $1,050 \mathrm{msec}$ in duration and coterminated with the US on reinforced trials. The US was a 50-msec train of $100 / \mathrm{sec} 4-\mathrm{mA}$ square-wave pulses produced by a constant-current generator and delivered to the right paraorbital region through \#32 gauge stainless steel sutures that were implanted in the skin about the orbit of the eye. One suture was located approximately $5 \mathrm{~mm}$ ventral to the extreme nasal extent, and the other approximately $5 \mathrm{~mm}$ caudal to the extreme lateral extent of the eye. All stimuli were under the control of electronic pulse generators and operated by a laboratory computer.

Closure of the rabbit's eye was monitored by an adaptation of the photoresistive transducer described by Gormezano and Gibbs (1988). The transducer, taped directly to the rabbit's head, communicated with the lid by a length of thread tied to a small permanent suture loop. Movements of the eyelid turned a counterweighted pulley wheel fixed to the axle of the transducer. The resulting signal was displayed on a polygraph, adjusted so that a $0.5-\mathrm{mm}$ eyelid closure produced a $1.0-\mathrm{mm}$ deflection of a recording pen.

Preparation. On each of 2 days prior to the start of training, each rabbit was handled for $10 \mathrm{~min}$. The next day, the rabbits were habituated to confinement in the restraining box for $1 \mathrm{~h}$. Their heads were then shaved, and the US electrodes and eyelid suture were implanted.

Procedure. Training was administered over 20 sessions. The 1 st session involved 36 trials, including three presentations of each of the reinforced cues $(\mathrm{A}, \mathrm{B}, \mathrm{C}, \mathrm{AB}, \mathrm{AC}, \mathrm{BC})$ and 18 presentations of the nonreinforced cue $(\mathrm{ABC})$. Each remaining session contained 96 trials, with 8 presentations of each of the reinforced cues and 48 presentations of the nonreinforced cue distributed in a pseudorandom order. The intertrial interval was $2 \mathrm{~min}$.

Scoring. An eyelid CR was scored when the graphic record indicated an eyelid closure of $0.5 \mathrm{~mm}$ or more, relative to the prestimulus baseline, during the interval $100-1,000 \mathrm{msec}$ following stimulus onset.

\section{Results and Discussion}

Figure 2 depicts the mean percentage of $\mathrm{CRs}$ during the one-term (A, B, or C), two-term (AB, AC, or BC), and three-term $(\mathrm{ABC})$ trial types over successive blocks of four discrimination sessions. It is apparent from the figure that the animals learned the negative patterning discrimination, eventually coming to respond less to the $\mathrm{ABC}$ compound, which was consistently nonreinforced, than to the one-term or two-term components of that compound, which were consistently reinforced. It is also apparent that, in contrast to the findings of Redhead and Pearce (1995a), responding to AB, AC, and BC was consistently greater than responding to $\mathrm{A}, \mathrm{B}$, and $\mathrm{C}$, and more separated from responding to $\mathrm{ABC}$.

Statistical analyses confirmed these observations. An analysis of variance (ANOVA) with stimulus type (A/B/C, $\mathrm{AB} / \mathrm{AC} / \mathrm{BC}, \mathrm{ABC}$ ) and training blocks (5 blocks of 4 sessions each) as factors revealed a significant main effect of stimulus type $[F(2,14)=11.37]$, a significant main effect of training blocks $[F(4,28)=57.04]$, and a significant interaction between stimulus type and training blocks $[F(8,56)=13.48, p \mathrm{~s}<.05]$. Independent $t$ tests consequent to the aforementioned interaction revealed that the advantage in responding that developed to the two-term stimuli, $\mathrm{AB} / \mathrm{AC} / \mathrm{BC}$, over $\mathrm{ABC}$ was statistically reliable from Training Block 3 onward [ts $(7)>3.77$ ], whereas the similar advantage that developed for the oneterm stimuli, A/B/C, was not reliable until Block $5[t(7)=$ $6.05, p \mathrm{~s}<.05]$. By direct comparison, there was significantly more responding to $\mathrm{AB} / \mathrm{AC} / \mathrm{BC}$ than to $\mathrm{A} / \mathrm{B} / \mathrm{C}$ at each block of training $[t \mathrm{~s}(7)>2.99, p \mathrm{~s}<.05]$. 


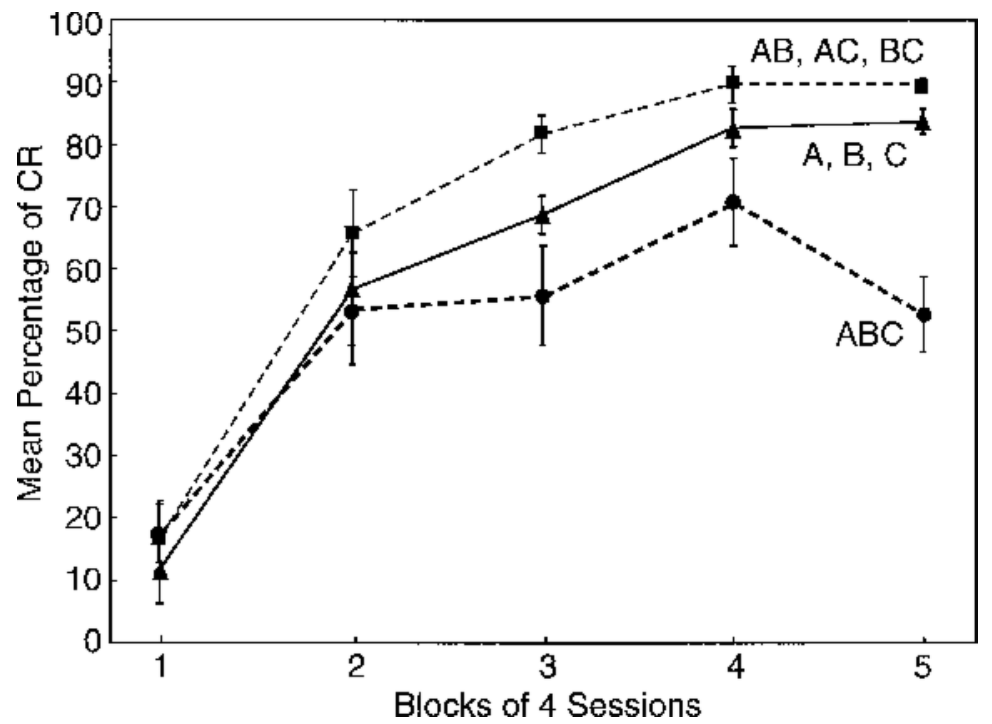

Figure 2. Mean percentage of conditioned response to the one-component CSs (A, B, and C), the two-component CSs (AB, AC, and BC), and $\mathrm{ABC}$ over blocks of four discrimination sessions in Experiment 1. The error bars represent the standard errors of the means.

The finding that the responding to $\mathrm{AB}, \mathrm{AC}$, and $\mathrm{BC}$ was greater than that to $\mathrm{A}, \mathrm{B}$, and $\mathrm{C}$, and more separated from the responding to $\mathrm{ABC}$, is as predicted by the Rescorla-Wagner model but is contrary to the predictions of the Pearce model and to the findings of Redhead and Pearce (1995a, Experiments 2, 3, and 4). We will offer some speculations as to the reasons for the discrepancy between our pattern of results and those of Redhead and Pearce in the General Discussion.

\section{EXPERIMENT 2}

In Experiment 2, we employed all of the same stimuli as we did in Experiment 1. Experiment 2 involved a summation design studied by Pearce et al. (1997) because it also exposes differential predictions of the RescorlaWagner (1972) and the Pearce (1987) models. In this case, different groups of animals were given reinforced training with either the single-stimuli, $\mathrm{A}+, \mathrm{B}+, \mathrm{C}+$, or the two-term stimuli, $\mathrm{AB}+, \mathrm{AC}+, \mathrm{BC}+$, before being tested for response to the three-term compound, $\mathrm{ABC}$, which contained the training stimuli. Figure 3 depicts the associative strengths predicted to accrue to the training cues, to $\mathrm{ABC}$, and to additional test cues (see below) for each group of animals, as predicted by the Pearce model (left graph) and by the Rescorla-Wagner model (right graph).

The notable prediction of the Pearce model, illustrated in Figure 3, is that the test responding to $\mathrm{ABC}$ should be no greater than the response to the training stimuli in the group trained with $\mathrm{A}+, \mathrm{B}+, \mathrm{C}+$, whereas the test responding to $\mathrm{ABC}$ should be greater than the response to the training stimuli in the group trained with $\mathrm{AB}+, \mathrm{AC}+$,
$\mathrm{BC}+$, and greater than in the alternative group. The predictions of the Rescorla-Wagner model, also illustrated in Figure 3, are quite different. That is, a greater responding is expected to $\mathrm{ABC}$ than to the training cues in both groups, and the magnitude of responding to $\mathrm{ABC}$ is expected to be greater in the group trained with $\mathrm{A}+, \mathrm{B}+$, and $\mathrm{C}+$ than in the group trained with $\mathrm{AB}+, \mathrm{AC}+$, and $\mathrm{BC}+$. The Pearce model predicts apparent summation effects only when there are cues common to the to-becombined stimuli, whereas the Rescorla-Wagner model predicts greater summation the fewer such common cues.

Pearce et al. (1997, Experiment 1), using pigeon autoshaping and visual cues, tested these specific contrasting predictions of the Rescorla-Wagner and Pearce models. In their experiment, the $\mathrm{A}, \mathrm{B}$, and $\mathrm{C}$ cues were represented by differently colored patterns that could be presented in the left, center, and right thirds, respectively, of the miniature television screen that was visible through the response key. The observed result was that there was more test responding to $\mathrm{ABC}$ following training with $\mathrm{AB}+$, $\mathrm{AC}+$ and $\mathrm{BC}+$, than following training with $\mathrm{A}+, \mathrm{B}+$, and $\mathrm{C}+$, in agreement with the Pearce model and contrary to the Rescorla-Wagner model.

Experiment 2 was an attempt to evaluate the same formal problem studied by Pearce et al. (1997). It differed in that we used the same eyelid conditioning preparation and the same visual, auditory, and vibrotactual cues as in Experiment 1. Although the primary focus was to assess any differences in responding to $\mathrm{ABC}$ in the two groups, the posttraining testing was also expanded to include not only the testing of $\mathrm{ABC}$, but also the testing of $\mathrm{A}, \mathrm{B}$, and $\mathrm{C}$ and of $\mathrm{AB}, \mathrm{AC}$, and $\mathrm{BC}$ in both groups. 

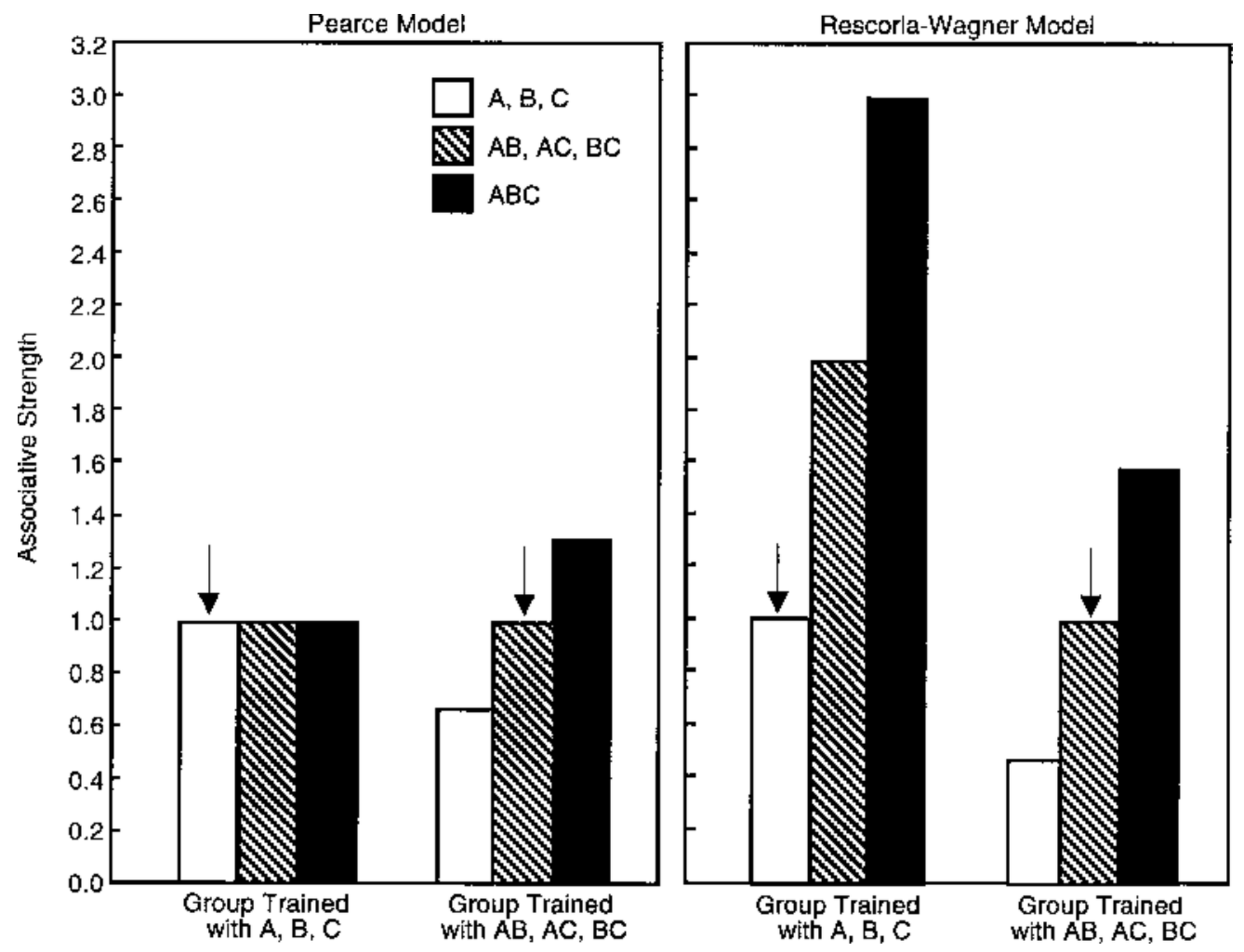

Figure 3. Predicted associative strength of training cues and of test cues composed of novel configurations of training cue components as predicted by a computer simulation based on the Pearce model (left graph) and by a computer simulation based on the Rescorla-Wagner model (right graph). The arrows indicate training cues for each group of animals.

\section{Method}

Animals. The animals were 16 experimentally naive male New Zealand white rabbits (Oryctolagus cuniculus) maintained and prepared in the same manner as those of Experiment 1.

Apparatus. The apparatus and stimuli were the same as those of Experiment 1.

Procedure. The study was run in two replications, each including 4 subjects that were trained with $\mathrm{A}+, \mathrm{B}+$, and $\mathrm{C}+$, and 4 with $\mathrm{AB}+, \mathrm{AC}+$, and $\mathrm{BC}+$, resulting in 8 subjects in each of the two treatment groups.

Training was administered over six sessions in Replication 1 and over five sessions in Replication 2, which was sufficient to bring all rabbits to more than $80 \%$ conditioned responding to each training CS. The first session involved 33 trials, including 11 presentations of each of the cues. All remaining sessions contained 72 trials, with 24 presentations of each of the cues distributed in a pseudorandom order. The intertrial interval was 2 min.

Testing was conducted in two sessions. Each test session began with 18 training trials, including six reinforced presentations of each of the three training cues. Testing immediately followed. In Test Session 1, the responding to $\mathrm{ABC}$ was assessed. The test trials were organized into blocks of 4 that included one presentation of each of the three training stimuli $(\mathrm{A}, \mathrm{B}$, and $\mathrm{C}$, or $\mathrm{AB}, \mathrm{AC}$, and $\mathrm{BC})$ and one presentation of $\mathrm{ABC}$, in balanced orders. There were 16 blocks of such test trials, 8 of which were reinforced and 8 nonreinforced, in an alternating sequence. In Test Session 2, the responding to the alternate training stimuli was assessed. The test trials were organized in blocks of six trials that included one presentation of each of $\mathrm{A}, \mathrm{B}$, $\mathrm{C}, \mathrm{AB}, \mathrm{AC}$, and $\mathrm{BC}$, in balanced orders, for all animals. There were
12 blocks of such test trials, 6 of which were reinforced and 6 nonreinforced, in an alternating sequence.

Scoring. Eyelid CRs were scored as in Experiment 1, but because the animals responded on virtually $100 \%$ of the test trials, the response measure reported in this experiment is the mean amplitude of eyelid closure.

\section{Results and Discussion}

Conditioned eyelid responding was acquired regularly in each of the two groups over training, with little difference between the groups. The mean frequency and amplitude of conditioned responding was greater in the group trained with $\mathrm{AB}+, \mathrm{AC}+, \mathrm{BC}+$ than in the group trained with $\mathrm{A}+, \mathrm{B}+, \mathrm{C}+$, but the differences did not attain statistical reliability.

The results of the posttraining test sessions are depicted in Figure 4, in terms of the overall mean amplitude of responding to the $\mathrm{A} / \mathrm{B} / \mathrm{C}, \mathrm{AB} / \mathrm{AC} / \mathrm{BC}$, and $\mathrm{ABC}$ test cues observed in each group of animals. This presentation ignores the fact that testing of the three stimulus types was done over two sessions, with the training stimuli included in both sessions but the ABC stimulus only in Session 1 and the alternate training stimuli only in Session 2. The simplified presentation was encouraged by the fact that there were no notable or statistically reliable session differences in the responding to the training stimuli that 


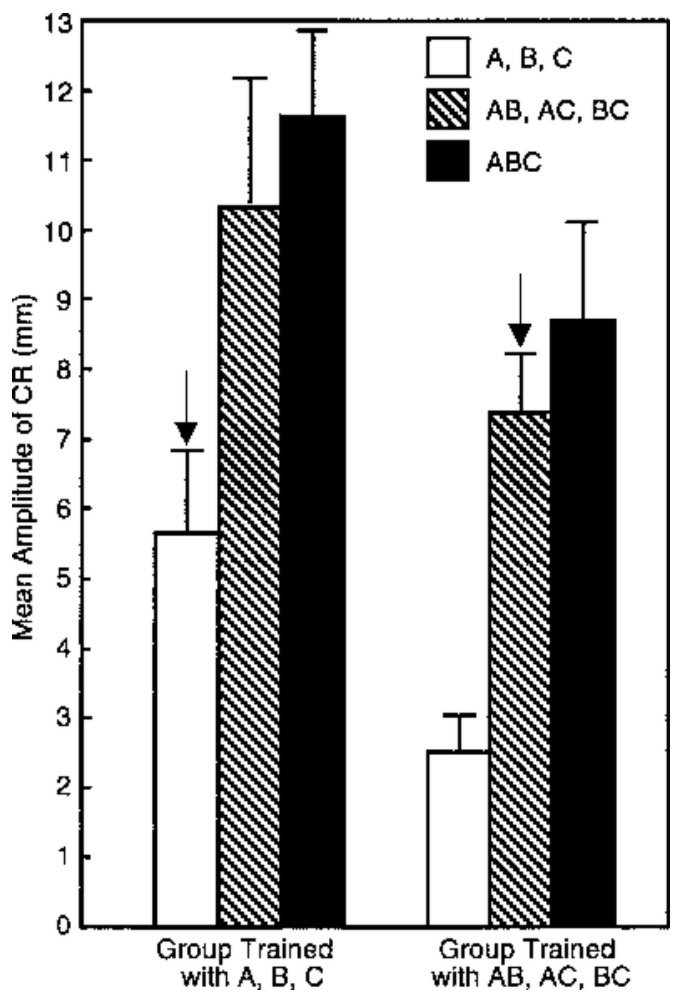

Figure 4. Mean amplitude of conditioned response to $A / B / C$, $\mathrm{AB} / \mathrm{AC} / \mathrm{BC}$, and $\mathrm{ABC}$ in Experiment 2. The arrows indicate training cues for each group of animals. The error bars represent the standard errors of the means.

were tested in both sessions. The data depicted suggest that summation, in the form of more responding to the novel $\mathrm{ABC}$ compound than to the previously reinforced components, was observed in both groups. They further suggest that the degree of summation in $A B C$ was greater in the group trained with $\mathrm{A}+, \mathrm{B}+, \mathrm{C}+$ than in the group trained with $\mathrm{AB}+, \mathrm{AC}+, \mathrm{BC}+$. Both of these findings are consistent with the Rescorla-Wagner model and contrary to the Pearce model. Adding to the support for the Rescorla-Wagner model is the apparent summation observed in the test responding of the group trained with $\mathrm{A}+, \mathrm{B}+$, and $\mathrm{C}+$ when tested on the $\mathrm{AB} / \mathrm{AC} / \mathrm{BC}$ stimuli: In an orderly way, the responding to the two-term stimuli was less than the responding to $\mathrm{ABC}$, but substantially greater than the responding to the individual cues and greater than the responding to the same stimuli of the group trained with $\mathrm{AB}+, \mathrm{AC}+$, and $\mathrm{BC}+$.

Statistical analyses confirmed the reliability of these observations. The data from the first test session were analyzed in a $2 \times 2$ ANOVA comparing each group's responding to its respective training cues with its responding to $\mathrm{ABC}$. This analysis revealed a significant group $\times$ test cue interaction $[F(1,14)=9.16, p<.05]$. Subsequent comparisons indicated that the greater responding to the $\mathrm{ABC}$ compound than to the training components was highly reliable in the case of the group trained with $\mathrm{A}+$,
$\mathrm{B}+$, and $\mathrm{C}+[t(7)=5.24, p<.05]$, but only approached reliability in the case of the group trained with $\mathrm{AB}+, \mathrm{AC}+$, $\mathrm{BC}+[t(7)=1.94]$. This difference was associated with a reliably greater responding to $\mathrm{ABC}$ in the group trained with $\mathrm{A}+, \mathrm{B}+$, and $\mathrm{C}+$ as compared with the group trained with $\mathrm{AB}+, \mathrm{AC}+$, and $\mathrm{BC}+[t(14)=2.69, p<.05]$.

The data from the second test session were similarly analyzed in a $2 \times 2$ ANOVA comparing responding to the groups' respective training cues $(\mathrm{A}+, \mathrm{B}+, \mathrm{C}+\mathrm{vs} . \mathrm{AB}+$, $\mathrm{AC}+, \mathrm{BC}+$ ) with their responding to the training cues of the opposite group. This analysis revealed a significant groups $\times$ test cue interaction $[F(1,14)=64.97, p<.05]$. Subsequent pairwise comparisons confirmed that the group trained with $\mathrm{A}+, \mathrm{B}+$, and $\mathrm{C}+$ responded more to the novel $\mathrm{AB}, \mathrm{AC}$, and $\mathrm{BC}$ compounds than to their training components $[t(7)=8.96, p<.05]$, and more to these two-term compounds than did the group that had been trained with them $[t(14)=3.99, p<.05]$.

These findings are consistent with the predictions of the Rescorla-Wagner model and contrary to those of the Pearce model and the findings of Pearce et al. (1997, Experiment 1).

\section{GENERAL DISCUSSION}

The results of the present experiments are consistent with previous eyeblink conditioning studies conducted in our laboratory (Bahçekapıl1, 1997) that have failed to replicate findings reported by Pearce and his associates in studies involving pigeon autoshaping (Pearce et al., 1997; Pearce \& Redhead, 1993; Redhead \& Pearce, 1995a). Pearce and his associates have consistently found support for predictions of the Pearce (1987) model that challenge the Rescorla and Wagner (1972) model. We have just as consistently obtained results which support the predictions of the Rescorla-Wagner model and challenge the Pearce model. We suppose that the different outcomes must ultimately be understood in terms of the different ways in which the same nominal experimental designs have been implemented in the two laboratories. And, although numerous differences are involved, the most obvious, given that the issue that divides the theories has to do with the nature of the functional stimulus, is that different stimuli have been employed in the two sets of studies.

The case for this interpretation is made more plausible by some results of the aforementioned studies in our laboratory by Bahçekapılı (1997). Bahçekapılı attempted to repeat, in eyeblink conditioning, a study of autoshaping reported by Pearce and Redhead (1993, Experiment 1), which compared the learning of a simple feature negative discrimination (e.g., $\mathrm{A}+, \mathrm{AB}-$ ) with the learning of a feature negative discrimination involving an additional common cue (i.e., AC+, ABC-). Pearce and Redhead implemented this problem by identifying $\mathrm{A}, \mathrm{B}$, and $\mathrm{C}$, respectively, as sets of red, green, and white pixels distributed on the face of a miniature TV screen. Their results were consistent with the prediction of the Pearce model, 
which is that the addition of the common cue should interfere with the discrimination. By the same token, they were contrary to the nonintuitive prediction of the RescorlaWagner model, that the addition of a common cue should facilitate a feature-negative discrimination. When Bahçekapilı (1997, Experiment 1), repeated this design in eyeblink conditioning, using the same auditory, visual, and vibrotactual stimuli employed in the present experiments, he observed just the opposite of Redhead and Pearce, and support for the Rescorla-Wagner model: Including an additional common cue in a feature-negative discrimination increased the degree of responding to the reinforced stimulus and, thereby, increased the separation between the reinforced and nonreinforced discriminanda.

Bahçekapılı (1997) questioned whether the difference between his findings and those of Pearce and Redhead might be due to the different possibilities for perceptual interaction among the stimuli employed in the two laboratories. It seemed likely that the white pixels added to the feature negative displays by Pearce and Redhead (1993, Experiment 1) might mask the presence versus absence of a red feature, whereas it seemed less likely that one of the auditory, visual, or vibrotactual stimuli that was employed by Bahçekapılı as an added cue would mask either of the remaining stimuli. Bahçekapılı (1997, Experiment 2) followed this reasoning with another conceptual replication of the Pearce and Redhead design, but employing only cues drawn from the auditory dimension and involving an added common cue that was either expected to produce masking, as suspected in the Pearce and Redhead study, or not expected to produce masking, as supposed in his previous study. The findings were quite clear: A feature negative discrimination, involving a tone and a siren, was interfered with by the addition of a common cue when the common cue was a white noise that might be expected to mask the discriminanda; however, the same discrimination was facilitated by the addition of a common cue when the common cue was a train of clicks, which, in the experimenter's judgment, did not appear to mask the discriminanda. Bahçekapılı concluded that the prediction of the Rescorla-Wagner model was upheld in his comparisons that attempted to avoid perceptual interactions, and suggested that the contrary results obtained by Pearce and Redhead, as well as in his noise condition, may have resulted from interactions among the stimuli. Similar reasoning may be appropriate in rationalizing the conflicting results of the present Experiment 1, in which stimuli from different modalities were used, as compared with the results of Redhead and Pearce (1995a, Experiment 1), who used stimuli quite similar to those of Pearce and Redhead (1993).

Our data are not the first to highlight the fact that different patterns of results, some consistent with a configural approach and others consistent with an elementistic approach, may be obtained using, ostensibly, the same comparisons, but different choices of stimuli. A notable case is the investigation of summation, where different results have been obtained in studies of pigeon auto- shaping as compared with other preparations. Although summation has been demonstrated in a wide variety of preparations and species, including rabbit eyeblink conditioning with stimuli from different modalities (e.g., Kehoe, Horne, Horne, \& Macrae, 1994; Whitlow \& Wagner, 1972), its occurrence in pigeon autoshaping has been notoriously unreliable (Pearce, Adam, Wilson, \& Darby, 1992; Rescorla, 1989), and researchers have attempted in several studies to discover the reasons for its elusiveness (e.g., Aydin \& Pearce, 1995, 1997; Pearce, George, Redhead, Aydin, \& Wynne, 1999; Pearce et al., 1997; Rescorla \& Coldwell, 1995). Some (e.g., Pearce et al., 1997) have concluded that the common failures to observe summation in pigeon autoshaping (together with the occasional successes) are consistent with the predictions of Pearce's (1987) configural theory; others (e.g., Rescorla $\&$ Coldwell, 1995) have suggested that the failures may be attributable to stimulus characteristics, so that with a different choice of stimuli, summation, consistent with the predictions of elementistic theories (Rescorla \& Wagner, 1972) may be obtained.

Rescorla and Coldwell (1995) failed to observe any summation in the keypecking of pigeons to compounds of separately trained localized visual CSs, despite various carefully controlled comparisons. In further experiments, they assessed summation by using the secondorder conditioning that accrued to a localized visual stimulus when it was followed by independently trained first-order stimuli, either in isolation or in compound. No evidence of summation was obtained with the use of compounds of two localized visual first-order stimuli, but summation effects were obtained with compounds of one diffuse auditory and one diffuse visual first-order stimulus, and with compounds of one diffuse auditory and one localized visual first-order stimulus. On the basis of these data, Rescorla and Coldwell suggested that perceptual interactions among localized visual stimuli might be responsible for the common failure to observe summation in autoshaping, and that summation may be observed if stimuli are chosen so as to reduce such interaction. In a final experiment, they attempted to prevent perceptual interactions among localized visual stimuli by presenting them in sequential, rather than simultaneous, compounds. In this case, they were again successful in obtaining summation. The authors concluded that "the localized stimuli conventionally employed in autoshaping experiments may show such substantial perceptual interaction as to recommend against their routine use for studying conditioning in compounds" (p. 314).

We can agree with Rescorla and Coldwell (1995), and point to the likelihood of perceptual interaction among the visual stimuli employed by Pearce et al. (1997) as the reason that their results were not the same as those that we observed in Experiment 2 with the same formal comparisons, but using stimuli from different modalities. It would be wrong, however, to single out the stimuli used in autoshaping experiments as peculiarly open to perceptual interactions. As previously described, the results of one 
of the eyeblink conditioning studies from our laboratory by Bahçekapılı (1997), using all auditory stimuli, showed apparent perceptual interaction with one set of stimuli, although not with another set. Likewise, Kehoe et al. (1994) did not see summation when an independently trained tone and noise were tested in compound, whereas they did see summation when an independently trained tone and light were tested in compound. Perceptual interactions are generally possible among the components of CS compounds. They are less likely to occur if one uses stimuli from different modalities, as in the two experiments reported here.

It is a given that the relationship between a compound and the components that are aggregated to form it depends on the nature of the components and the way in which they are aggregated. Garner $(1970,1974)$ summarized the pattern of findings from an extensive body of research on stimulus classification and scaling by distinguishing between stimulus compounds that appear to involve "separable" components and those that appear to involve "integral" components. Separable components are ones that appear to be processed the same in compound as in isolation. Integral components are ones that appear to combine in more holistic fashion, and not to be processed the same in compound as in isolation. Among the evidence cited by Garner in support of this distinction is that some compounds (with separable dimensions) lead to a city-block metric in multidimensional scaling, whereas others (with integral dimensions) lead to a Euclidean metric. The Rescorla-Wagner model (Rescorla \& Wagner, 1972; Wagner \& Rescorla, 1972), including its conception of the stimulus, was designed to deal with compounds of cues that Garner would consider separable, and which can, perhaps, be best assured when the components are drawn from different sensory modalities. Considerable available data from experiments done with such stimuli, including the results of the present studies, support this model. The Pearce model $(1987,1994)$, on the other hand, has also been supported by the results of formally identical experimental comparisons (e.g., Pearce et al., 1997; Pearce \& Redhead, 1993; Redhead \& Pearce, 1995a) using compounds of cues that have been argued to be more likely to be integral. Although there are cases that do not fit neatly with this categorization (see, e.g., Brandon, Vogel, \& Wagner, 2000; Redhead \& Pearce, 1995b, Experiment 2), it is tempting to conclude that neither conception is more or less correct, but that each is more or less appropriate to different kinds of stimuli. ${ }^{2}$

Accepting this conclusion does not require one to assume different learning rules depending on the stimuli involved. As indicated in the present introduction, the Pearce model computes similarly to the Rescorla-Wagner model in major respects. Wagner and Brandon (2001) have shown that the similarity runs deeper. Space does not allow a full exposition of their analysis. Suffice it to say that they demonstrated that the Pearce model, as well as the Rescorla-Wagner model, can be rendered in elementistic terms, employing the Rescorla-Wagner learn- ing rule. According to Wagner and Brandon, the two conceptions differ from each other, as well as from other possible conceptions, in the way in which they deal with context dependencies in stimulus compounding.

Wagner and Brandon (2001) made use of the common notion (e.g., Estes, 1950; Konorski, 1948) that nominal stimuli activate sets of elements, each of which can acquire associative strength. The conception of the stimulus employed by Rescorla and Wagner (1972; Wagner \& Rescorla, 1972) would suppose that when stimuli A and $\mathrm{B}$ are presented in compound, the compound activates not only the elements activated by A and B in isolation, but also a (smaller) set of added elements that represent the conjunction of the two stimuli. Wagner and Brandon show how the contrasting conception of the stimulus employed by Pearce $(1987,1994)$ is equivalent to supposing that when A and B are presented in compound, the compound does not activate all of the elements activated by $\mathrm{A}$ and $\mathrm{B}$ in isolation, but, according to specified rules, activates only a fraction of each, so that a compound is represented by the same number of elements as is each of the components in isolation. By this design, the contextdependent elements are not elements that are added during compounding, as in the Rescorla-Wagner conception, but the elements that are "inhibited" during compounding. Wagner and Brandon further presented what they termed a "replaced-elements" conception that involves both the addition and the inhibition of elements when stimuli are compounded. In this conception, it is supposed that when A and B are presented together, some of the elements representing $\mathrm{A}$ alone are replaced by elements representing $\mathrm{A}$ in compound with $\mathrm{B}$, and, likewise, some of the elements representing $\mathrm{B}$ alone are replaced by elements representing B in compound with A.

We recommend this structure as a useful framework within which to address some experimental comparisons involving separable stimuli that are not fully compatible with either the Rescorla-Wagner model or the Pearce model, but may be better handled by the replaced-elements conception for reason of its similarity to both. A case in point is the overall pattern of generalization decrement that occurs as a result of adding as compared to removing a stimulus component (see Brandon et al., 2000). The Pearce model correctly predicts a decrement as a result of adding a cue, as well as removing a cue; the RescorlaWagner model correctly predicts more of a decrement from removing a cue than from adding a cue; the replacedelements model uniquely predicts the phenomena asserted by each theory.

It is possible that the framework may also be useful in helping us to rationalize why the results from the same formal problem can produce very different results when involving stimuli drawn from different modalities versus the same modality, as in the case of the present studies versus those of Pearce et al. (1997) and Redhead and Pearce (1995a). Whether the replaced-elements conception predicts results like those of the added-elements (RescorlaWagner) conception or the inhibited-elements (Pearce) 
conception depends, in part, on the proportion of the elements that represent any stimulus that are assumed to be context-independent (i.e., to occur equally when the stimulus is presented alone or in context with other stimuli) and the proportion that are assumed to be context dependent (i.e., to be replaced by other elements when the stimulus is presented in compound). It is possible that separable stimuli are ones that have a large proportion of context-independent elements and, thus, lead to results more similar to those predicted by an added-elements model, whereas integral stimuli are ones that have a small proportion of context-independent elements, and, thus, produce results more similar to those predicted by an inhibited-elements model.

\section{REFERENCES}

Aydin, A., \& Pearce, J. M. (1994). Prototype effects in categorization by pigeons. Journal of Experimental Psychology: Animal Behavior Processes, 20, 264-277.

Aydin, A., \& Pearce, J. M. (1995). Summation in autoshaping with short- and long-duration stimuli. Quarterly Journal of Experimental Psychology, 48B, 215-234.

Aydin, A., \& Pearce, J. M. (1997). Some determinants of response summation. Animal Learning \& Behavior, 25, 108-121.

BAHÇEKAPã̃õ H. G. (1997). An evaluation of Rescorla and Wagner's elementistic model versus Pearce's configural model in discrimination learning. Unpublished doctoral dissertation, Yale University.

Brandon, S. E., Vogel, E. H., \& Wagner, A. R. (2000). A componential view of configural cues in generalization and discrimination in Pavlovian conditioning. Behavioural Brain Research, 110, 67-72.

Estes, W. K. (1950). Toward a statistical theory of learning. Psychological Review, 57, 94-104.

GARNER, W. R. (1970). The stimulus in information processing. American Psychologist, 25, 350-358.

GARNER, W. R. (1974). The processing of information and structure. Potomac, MD: Erlbaum.

Gormezano, I., \& GiBBs, C. M. (1988). Transduction of the rabbit's nictitating membrane response. Behavior Research Methods, Instruments, \& Computers, 20, 18-21.

Kehoe, E. J., Horne, A. J., Horne, P. S., \& Macrae, M. (1994). Summation and configuration between and within sensory modalities in classical conditioning of the rabbit. Animal Learning \& Behavior, 22, 19-26.

KonORSKI, J. (1948). Conditioned reflexes and neuron organization. Cambridge: Cambridge University Press.

Pearce, J. M. (1987). A model for stimulus generalization in Pavlovian conditioning. Psychological Review, 87, 532-552.

Pearce, J. M. (1994). Similarity and discrimination: A selective review and a connectionist model. Psychological Review, 101, 587-607.

Pearce, J. M., Adam, J., Wilson, P. N., \& Darby, R. J. (1992). Effects of discrimination training on responding during a compound conditioned stimulus. Journal of Experimental Psychology: Animal Behavior Processes, 18, 379-386.

Pearce, J. M., Aydin, A., \& Redhead, E. S. (1997). Configural analysis of summation in autoshaping. Journal of Experimental Psychology: Animal Behavior Processes, 23, 84-94.

Pearce, J. M., George, D. N., Redhead, E. S., Aydin, A., \& Wynne, C. (1999). The influence of background stimuli on summation during autoshaping. Quarterly Journal of Experimental Psychology, 52B, 53-74.

Pearce, J. M., \& Redhead, E. S. (1993). The influence of an irrelevant stimulus on two discriminations. Journal of Experimental Psychology: Animal Behavior Processes, 19, 180-190.

Pearce, J. M., \& Wilson, P. N. (1990a). Configural associations in discrimination learning. Journal of Experimental Psychology: Animal Behavior Processes, 16, 250-261.
Pearce, J. M., \& Wilson, P. N. (1990b). Feature-positive discrimination learning. Journal of Experimental Psychology: Animal Behavior Processes, 16, 315-325.

Pearce, J. M., \& Wilson, P. N. (1991a). Effects of extinction with a compound conditioned stimulus. Journal of Experimental Psychology: Animal Behavior Processes, 17, 151-162.

Pearce, J. M., \& Wilson, P. N. (1991b). Failure of excitatory conditioning to extinguish the influence of a conditioned inhibitor. Journal of Experimental Psychology: Animal Behavior Processes, 17, 519-529.

Redhead, E. S., \& Pearce,J. M. (1995a). Similarity and discrimination learning. Quarterly Journal of Experimental Psychology, 48B, 46-66.

Redhead, E. S., \& Pearce, J. M. (1995b). Stimulus salience and negative patterning. Quarterly Journal of Experimental Psychology, 48B, 67-83.

Redhead, E. S., \& Pearce, J. M. (1998). Some factors that determine the influence of a stimulus that is irrelevant to a discrimination. Journal of Experimental Psychology: Animal Behavior Processes, 24, 123-135.

REsCorla, R. A. (1989). Redundant treatments of neutral and excitatory stimuli in autoshaping. Journal of Experimental Psychology: Animal Behavior Processes, 15, 212-223.

Rescorla, R. A., \& Coldwell, S. E. (1995). Summation in autoshaping. Animal Learning \& Behavior, 23, 314-326.

Rescorla, R. A., \& WAgner, A. R. (1972). A theory of Pavlovian conditioning: Variations in the effectiveness of reinforcement and nonreinforcement. In A. H. Black \& W. F. Prokasy (Eds.), Classical conditioning II (pp. 64-99). New York: Appleton-Century-Crofts.

SPENCE, K. W. (1952). The nature of the response in discrimination learning. Psychological Review, 59, 89-93.

WAGNeR, A. R. (1971). Elementary associations. In H. H. Kendler \& J. T. Spence (Eds.), Essays in neobehaviorism: A memorial volume to Kenneth W. Spence (pp. 187-213). New York: Appleton-CenturyCrofts.

Wagner, A. R. \& Brandon, S. E. (2001). A componential theory of Pavlovian conditioning. In R. R. Mowrer \& S. B. Klein (Eds.), Handbook of contemporary learning theories (pp. 23-64). Mahwah, NJ: Erlbaum.

Wagner, A. R., \& Rescorla, R. A. (1972). Inhibition in Pavlovian conditioning: Application of a theory. In R. A. Boakes \& M. S. Halliday (Eds.), Inhibition and learning (pp. 301-336). London: Academic Press.

Whit LOW, J. W., JR., \& WAGNER, A. R. (1972). Negative patterning in classical conditioning: Summation of response tendencies to isolable and configural components. Psychonomic Science, 27, 299-301.

Wilson, P. N., \& Pearce, J. M. (1989). A role for stimulus generalization in conditional discrimination learning. Quarterly Journal of Experimental Psychology, 41B, 243-273.

Wilson, P. N., \& Pearce, J. M. (1992). A configural analysis for featurenegative discrimination learning. Journal of Experimental Psychology: Animal Behavior Processes, 18, 265-272.

Woodbury, C. B. (1943). The learning of stimulus patterns by dogs. Journal of Comparative Psychology, 35, 29-40.

Young, D. B., \& Pearce, J. M. (1984). The influence of generalization decrement on the outcome of a feature positive discrimination. Quarterly Journal of Experimental Psychology, 36B, 331-352.

\section{NOTES}

1. In the computer simulations that led to the functions described in Figures 1 and 3, parameter values were specified so that the learning rates would be approximately equal according to the two models. For the Rescorla-Wagner model, $\alpha$ was set at .05 for nominal elements and .0125 for configural elements; $\beta$ was set at 1 for reinforced trials and .5 for nonreinforced trials. For the Pearce model, $\beta$ was set at .05 for reinforced trials and .025 for nonreinforced trials. The differential predictions of the two models relevant to Experiments 1 and 2 do not depend on special parameter selections.

2. We have emphasized the same possibility as have Rescorla and Coldwell (1995), that the differing results of our laboratory, versus that of Pearce and his colleagues, are likely to be attributable to the different 
stimuli employed as CSs. Another possibility suggested by an anonymous reviewer is that they could be attributed to a differing functional salience of the background stimuli with which the CSs are compounded. Pearce (1994) has pointed out that whereas his configural account does not predict summation effects when two separately trained stimuli are compounded, it does predict summation if the separately trained stimuli and the test configuration are assumed to be in compound with contextual stimuli that are otherwise nonreinforced-that is, if one assumes that a nominal design of training $\mathrm{A}+, \mathrm{B}+$, and testing $\mathrm{AB}$ is theoretically represented as the training of $\mathrm{AX}+, \mathrm{BX}+, \mathrm{X}-$, and testing $\mathrm{ABX}$ (see Pearce et al., 1992, for computational details). Thus, the summation observed in Experiment 2, versus the absence of summation reported by Pearce et al. (1997), might well be rationalized by Pearce in terms of more effective contextual stimuli in the former case than in the latter. The same reasoning could be applied to the negative patterning results of Exper- iment 1 versus those of Redhead and Pearce (1995a). However, for Pearce to predict a persisting greater responding to the (nominal) twoelement compounds than to the one-element stimuli, during that phase of discrimination learning when both are more responded to than the negative three-term compound, as observed in Experiment 1, would require the relatively implausible assumption that the contextual cues were considerably more salient than the nominal cues. The general possibility of appealing to more or less salient contextual cues in the two laboratories is made less attractive by virtue of the fact that it cannot predict the aforementioned findings of Bahçekapılı (1997) versus those of Redhead and Pearce (1995a) in feature-negative discrimination learning.

(Manuscript received April 10, 2000; revision accepted for publication August 25, 2000.) 